Anthropol. Sci. 105(2), 99-116, 1997

\title{
A Comparative Study on Histology of Testes in Macaca nemestrina, M. fascicularis and M. fuscata
}

\author{
Tomoo Enomoto ${ }^{1}$, Kiyoaki Matsubayashi ${ }^{2}$, Mayumi NaKano ${ }^{1}$, \\ Yasukazu Nagato ${ }^{1}$, Tuty L. YusuF ${ }^{3}$, and Dondin Sajuthi ${ }^{3}$ \\ 1 Tokai University School of Medicine, Isehara, Kanagawa, \\ 259-11 Japan \\ 2 Primate Research Institute, Kyoto University, Inuyama, Aichi, \\ 484 Japan \\ 3 Primate Research Center, Bogor Agricultural University, \\ Jalan Raya Pajajaran, Bogor, Indonesia
}

Received September 25, 1996

\begin{abstract}
For the purpose of examining hypotheses on the evolutionary mechanism of testis morphology, histological comparisons of spermatogenetic activities were carried out in three macaque species. Testis samples were obtained by biopsies from six adult crab-eating macaques, six adult pig-tailed macaques and five adult Japanese macaques. In the Japanese macaques, samples were taken twice in October (mating season) and April (non-mating season), respectively. Microscopic observations revealed that some seminiferous tubules of the pig-tailed macaques showed characteristic features of degeneration, which were not found in the other two species. The acrosomic system of the spermatids of crab-eating macaques was most developed, compared with the other two species. Seminiferous tubules showing active spermiogenesis were frequently found in crab-eating macaques and in pig-tailed macaques, compared with Japanese macaques in the non-mating season. The seminiferous epithelia in stages containing only one type of spermatids were frequently observed in pig-tailed macaques, compared with those in crab-eating macaques and in Japanese macaques in the mating season. These findings suggest that spermatogenic activity is most prominent in the crab-eating macaques and that the mechanism of sperm competition has affected testicular architecture of this species in the course of its evolution.
\end{abstract}

Key Words: spermatogenesis, sperm competition, comparative study, macaques, Macaca fuscata, Macaca nemestrina, Macaca fascicularis

\section{INTRODUCTION}

The structure of testes of extant primate species is expected to be obtained through evolutionary processes. Although several hypotheses have been proposed to explain differences of testis structure among primate species including humans (Smith, 1984), its descent is still a complicated problem. For the purpose of examining the hypotheses, detailed comparisons of the histology of tests should be carried out in closely related species. 
There are many studies on testis histology of primates, such as Cercopithecus aethiops (Clermont, 1969), Macaca mulatta (Clermont and Leblond, 1955, 1959; Cavicchia and Dym, 1978; Dym and Cavicchia, 1978), Macaca arctoides (Clermont and Antar, 1973; Cavacchia and Dym, 1978; Dym and Cavacchia, 1978), Macaca nemestrina (Gondos and Zemjanis, 1970), Macaca fuscata fuscata (Tiba and Nigi, 1975, 1980) and Homo sapiens (Heller and Clermont, 1963, Clermont, 1963, 1966). These studies mainly focused on the renewal of germ cells, architecture of spermatogenic cells, and/or the spermatogenic cycle of the epithelium, and, therefore, comparative studies on testis histology have been ignored.

The sperm competition hypothesis was proposed (Short, 1979; Harvey and Harcourt, 1984) to explain sexual dimorphism and differences of genital morphology among primates. The hypothesis predicts that spermatogenic activity is associated with frequencies of ejaculations and also correlates with mating system type. To test the hypothesis, the capacity for continuous and rapid sperm production to enable frequent ejaculation must be evaluated. Therefore, the present study aims to compare histological characteristics of spermatogenesis in three macaque species, Macaca nemestrina, $M$. fascicularis and $M$. fuscata and to discuss that sperm competition has affected their genital morphology.

\section{METHODS}

This study was carried out in accordance with the "Guiding Principles for Animal Experiments Using Nonhuman Primates" of the Primate Society of Japan and also the "Guide for the care and use of laboratory primates" of Primate Research Institute, Kyoto University. The pig-tailed and the crab-eating macaque do not show obvious seasonal change in their reproduction, but the Japanese macaque is a seasonal breeder (Oi, 1996). Testicular samples were obtained from six pig-tailed and six crab-eating macaques, that had been kept in individual cages $(70 \times 60 \times 90 \mathrm{~cm})$ or in large cages $(10 \times 4 \times 3 \mathrm{~m})$ with room temperature at $27^{\circ} \mathrm{C}$ and relative humidity at 80 to $90 \%$ of indoor housing with artificial lighting for about three years at the Primate Research Center, Bogor Agricultural University, Indonesia (Table 1). Testicular specimens of Japanese macaques were taken successively in the mating (October) and non-mating (April) seasons from five adult males. The animals had been kept under laboratory conditions for 3 to 12 years before the experiments. They were kept in individual cages $(90 \times 65 \times 82 \mathrm{~cm})$ in an air-conditioned room with artificial lighting (light on between 06:00 and 18:00) with room temperature at $20 \pm 5^{\circ} \mathrm{C}$ and relative humidity at $60 \pm 15 \%$ at the Primate Research Institute, Kyoto University, Japan (Table 1). Testis size was measured for width, height and depth of both testes over scrotum and the volume was calculated as the sum of ellipsoid bodies. Tissue samples (less than $2 \times 2 \times 2 \mathrm{~mm}$ ) were excised from each animal under anesthesia with ketamine hydrochloride $(10 \mathrm{mg} / \mathrm{kg})$. Obtained samples were fixed with $10 \%$ formalin for Macaca nemestrina and M. fascicularis or Bouin's solution for 
M. fuscata. Thereafter, samples were embedded in paraffin and sectioned at a thickness of $4 \mu \mathrm{m}$. The sections were stained with hematoxylin and eosin for general observations, and periodic acid-Schiff reaction (PAS) and hematoxylin for making clear the acrosomic system.

Table. 1. The list of samples

\begin{tabular}{|c|c|c|c|}
\hline Male & age* & Condition & $\begin{array}{c}\text { Duration of } \\
\text { Captivity (year) }\end{array}$ \\
\hline \multicolumn{4}{|c|}{ M. fascicularis } \\
\hline 1697 & 7 & Individual & 2 \\
\hline 4998 & 10 & Individual & 2 \\
\hline 72 & 7 & Individual & 4 \\
\hline 108 & 7 & Individual & 3 \\
\hline 114 & $8-9$ & Individual & 3 \\
\hline 213 & 10 & Group & 3 \\
\hline \multicolumn{4}{|c|}{ M. nemestrina } \\
\hline 145 & 8 & Individual & 3 \\
\hline 100 & $>15$ & Alpha male & 3 \\
\hline 277 & $>15$ & Alpha male & 3 \\
\hline 236 & $>15$ & Alpha male & 3 \\
\hline 150 & 15 & Alpha male & 3 \\
\hline 235 & old & Alpha male & 3 \\
\hline \multicolumn{4}{|c|}{ M. fuscata (April) } \\
\hline Akuta & 13 & Individual & 10 \\
\hline Kojiro & 10 & Individual & 12 \\
\hline Saki & 10 & Individual & 11 \\
\hline Jiro & 13 & Individual & 10 \\
\hline Ryota & 9 & Individual & 3 \\
\hline \multicolumn{4}{|c|}{ M. fuscata (October) } \\
\hline Akuta & 13 & Individual & 10 \\
\hline Kojiro & 10 & Individual & 12 \\
\hline Saki & 10 & Individual & 11 \\
\hline Jiro & 13 & Individual & 10 \\
\hline Ryota & 9 & Individual & 3 \\
\hline
\end{tabular}

*All ages except for Japanese macaques were estimated.

Individual: Kept in individual cages. Group: Kept in a group cage. Alpha male: Alpha male of the group.

Two steps of spermatogenesis can be noticed, namely spermatocytogenesis and spermiogenesis. In the former phase, spermatogonia in the seminiferous epithelium undergo a series of divisions and at the final step produce spermatocytes. As an index of spermatocytogenetic activity, the rate of seminiferous tubules including spermatocytes was recorded (Fig. 1). The spermatocytes undergo two maturation divisions and produce spermatids. Thereafter, in the phase of spermiogenesis, the spermatids go through a 
sequence of cytological transformations. The activity of spermiogenesis was estimated by two indices. One of which is the ratio of tubules without spermatids in the maturation phase. The stages of the cycle of seminiferous epithelium in these tubules coincide with stages IV to X of Japanese macaques (Nagato et al., 1994) (Fig. 1). Second, tubules containing spermatids of the maturation phase were divided into three degrees according to the concentration of spermatids as shown in Figs. 2 to 4.

Statistical differences were evaluated with a two-tailed $t$-test and analysis of variance (ANOVA).

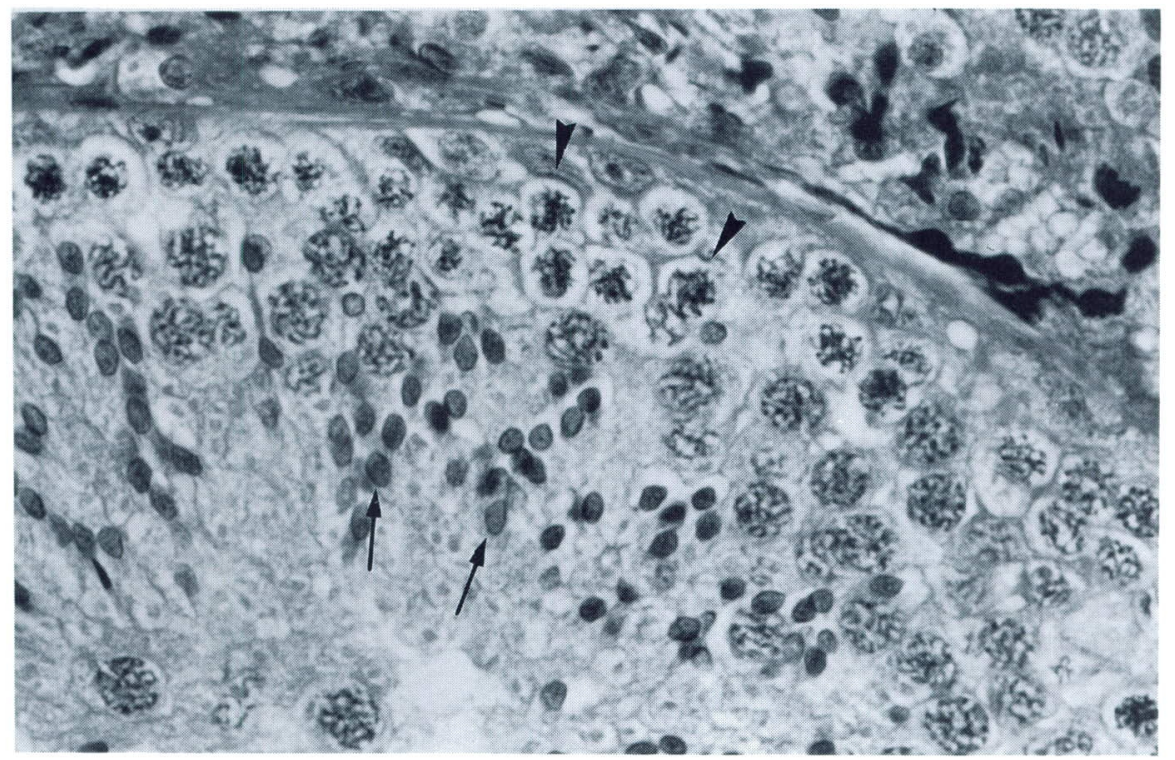

Fig. 1. Seminiferous tubules without spermatids of the maturation phase. Macaca fuscata (Saki, October), HE, $\times 400$. Arrow points: spermatocytes; arrows: spermatids.

\section{RESULTS}

\section{Testis volume}

The testis volume was different among four groups of species/seasons by analysis of variance $(\mathrm{ANOVA})(\mathrm{F}=17.934, \mathrm{df}=3, P<0.001)$ (Table 2). Statistical differences could not be detected in testis volume among crab-eating macaques, pig-tailed macaques, and Japanese macaques of non-mating season by $t$-tests. The testis volume of Japanese macaques in the mating season were significantly larger than other groups (vs. crab-eating macaques, $\mathrm{df}=9, t=7.015, P<0.001$; vs. pig-tailed macaques, $\mathrm{df}=9$, $t=5.448, P<0.001$, and vs. Japanese macaques of the non-mating season, paired $t$-test, $\mathrm{df}=4, t=12.483, P<0.001)$. 
Table 2. The size of testes

\begin{tabular}{|c|c|c|c|}
\hline \multirow{2}{*}{ Male } & \multicolumn{2}{|c|}{ Testis size $(\mathrm{mm})$} & \multirow{2}{*}{$\begin{array}{l}\text { Total testis volume } \\
(\mathrm{ml})\end{array}$} \\
\hline & right & left & \\
\hline \multicolumn{4}{|c|}{ (a) M. fascicularis } \\
\hline 1697 & $29 \times 27 \times 24$ & $38 \times 28 \times 28$ & 25.4 \\
\hline 4998 & $34 \times 29 \times 28$ & $38 \times 28 \times 32$ & 32.3 \\
\hline 72 & $36 \times 28 \times 26$ & $39 \times 30 \times 27$ & 30.3 \\
\hline 108 & $32 \times 25 \times 24$ & $35 \times 25 \times 25$ & 21.5 \\
\hline 114 & $38 \times 29 \times 28$ & $39 \times 28 \times 28$ & 32.2 \\
\hline 213 & $46 \times 37 \times 38$ & $48 \times 35 \times 32$ & 62.0 \\
\hline MeantS.D. & & & $33.9 \pm 14.4$ \\
\hline \multicolumn{4}{|c|}{ (b) $M$. nemestrina } \\
\hline 145 & $28 \times 27 \times 27$ & $28 \times 27 \times 26$ & 21.0 \\
\hline 100 & $40 \times 33 \times 33$ & $44 \times 36 \times 36$ & 52.7 \\
\hline 277 & $39 \times 27 \times 29$ & $37 \times 28 \times 28$ & 31.2 \\
\hline 236 & $48 \times 37 \times 36$ & $49 \times 39 \times 34$ & 67.5 \\
\hline 150 & $42 \times 31 \times 29$ & $42 \times 33 \times 33$ & 43.7 \\
\hline 235 & $44 \times 34 \times 33$ & $45 \times 35 \times 36$ & 55.5 \\
\hline Mean \pm S.D. & & & $45.3 \pm 17.0$ \\
\hline
\end{tabular}

\begin{tabular}{llll}
\hline (c) $M$. fuscata (Non-mating season) & & \\
Akuta & $50 \times 35 \times 29$ & $54 \times 37 \times 28$ & 55.9 \\
Kojiro & $54 \times 29 \times 24$ & $52 \times 28 \times 26$ & 39.5 \\
Saki & $46 \times 35 \times 26$ & $49 \times 32 \times 23$ & 40.8 \\
Jiro & $55 \times 34 \times 28$ & $53 \times 38 \times 27$ & 55.9 \\
Ryota & $48 \times 32 \times 24$ & $48 \times 32 \times 25$ & 39.4 \\
\hline Mean \pm S.D. & & $46.3 \pm 8.8$ \\
& & & \\
(d) $M$. fuscata (Mating season) & & 121.9 \\
Akuta & $65 \times 47 \times 40$ & $61 \times 49 \times 37$ & 92.2 \\
Kojiro & $62 \times 39 \times 40$ & $58 \times 38 \times 36$ & 94.8 \\
Saki & $61 \times 42 \times 34$ & $61 \times 44 \times 35$ & 127.0 \\
Jiro & $72 \times 49 \times 40$ & $64 \times 44 \times 36$ & 85.1 \\
Ryota & $59 \times 38 \times 38$ & $59 \times 41 \times 32$ & $104.2 \pm 18.9$ \\
\hline Mean \pm S.D. & & & \\
\hline
\end{tabular}

The ANOVA revealed that the testis volume was significantly different among groups $(\mathrm{F}=17.934$, $\mathrm{df}=3, P<0.001$ ). Significant differences were shown among (a) vs. (d), (b) vs. (d) and (c) vs. (d) at $P<0.001$.

\section{Tubules excluding spermatogenesis}

In three testicular specimens out of six of the pig-tailed macaques, there were seminiferous tubules in which spermatogenesis was eliminated (Fig. 5). The epithelia of these tubules were lined with epithelial cells (i.e. Sertoli cells) excluding spermatogenic 
cells. Some of them showed characteristics of hyalinization (Table 3, Fig. 6). This type of tubule was not found in specimens of crab-eating macaques nor Japanese macaques (Tables 4 and 5).

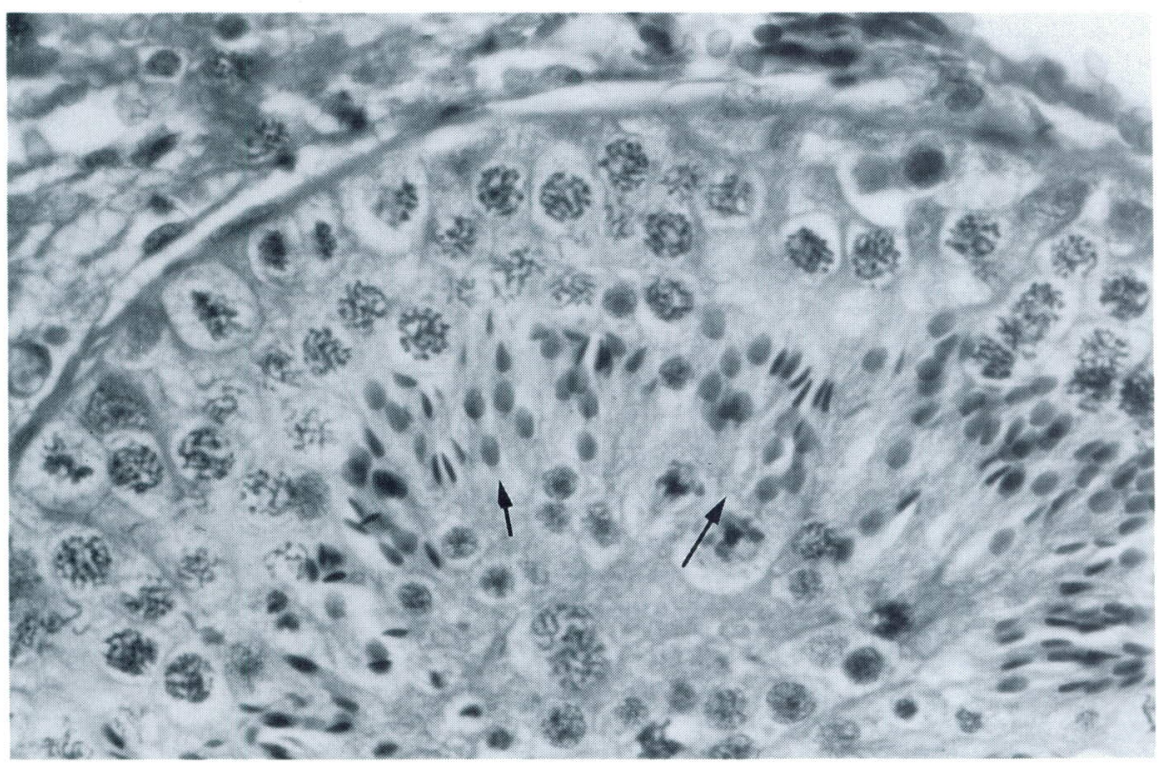

Fig. 2. Seminiferous tubules with active spermiogenesis. Macaca fuscata (Saki, October), HE, $\times 400$. Spermatids of the maturation phase (arrows) concentrate at the top of the epithelium.

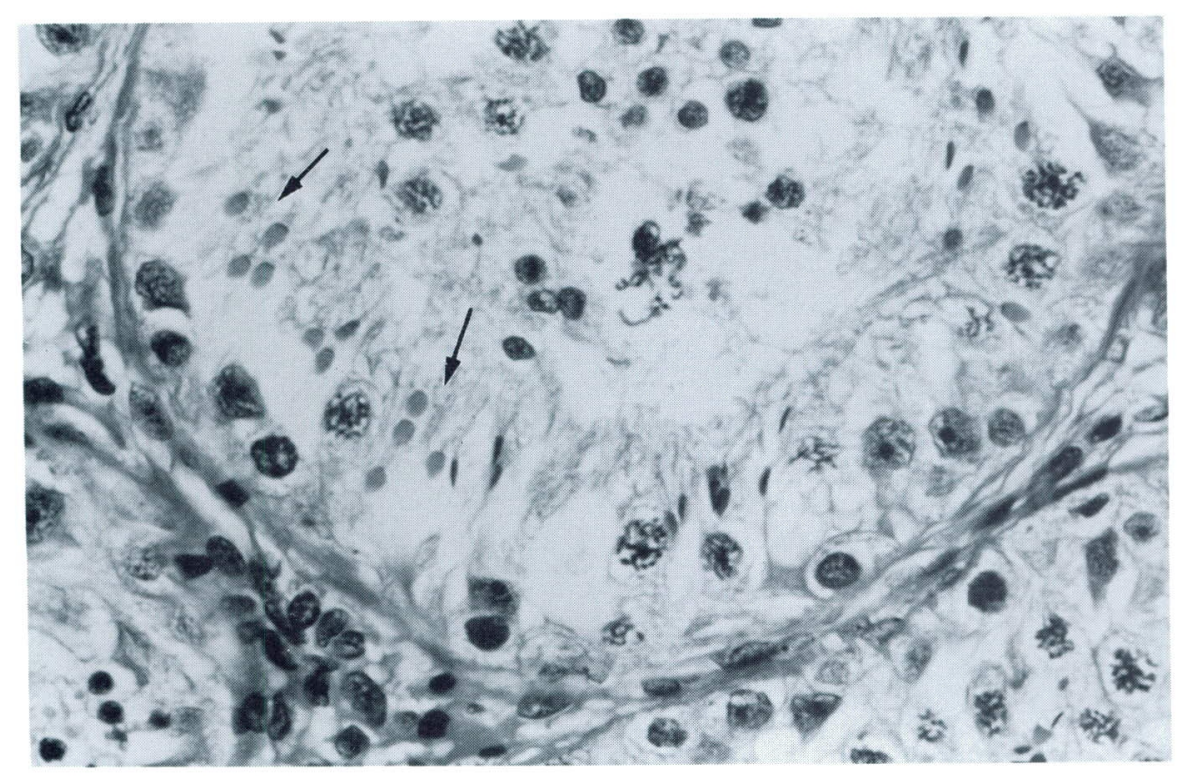

Fig. 3. Seminiferous tubules with medium spermiogenesis. Macaca fuscata (Saki, April), HE, $\times 400$. Spermatids of the maturation phase (arrows) are found in clusters but not concentrated. 


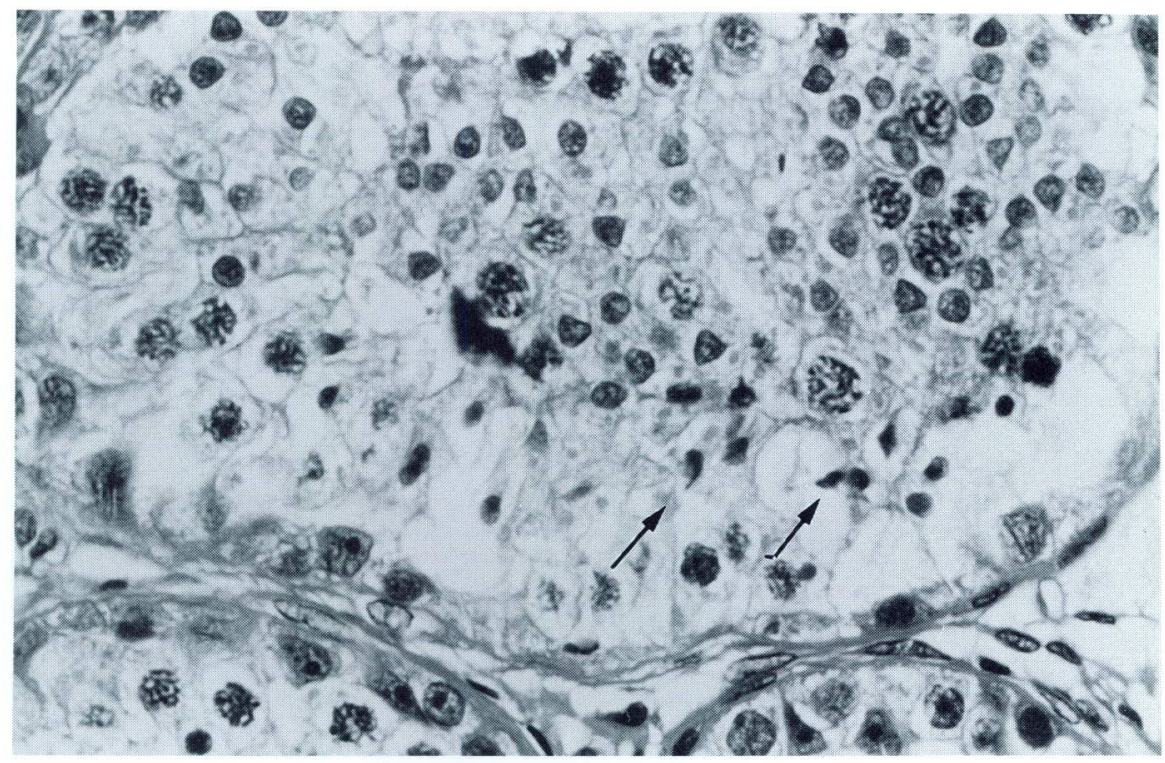

Fig. 4. Seminiferous tubules with poor spermiogenesis. Macaca fuscata (Saki, April), HE, $\times 400$. Spermatids of the maturation phase (arrows) are scattered in the epithelium. Many of them show degenerating characteristics (refer to Enomoto et al., 1995).

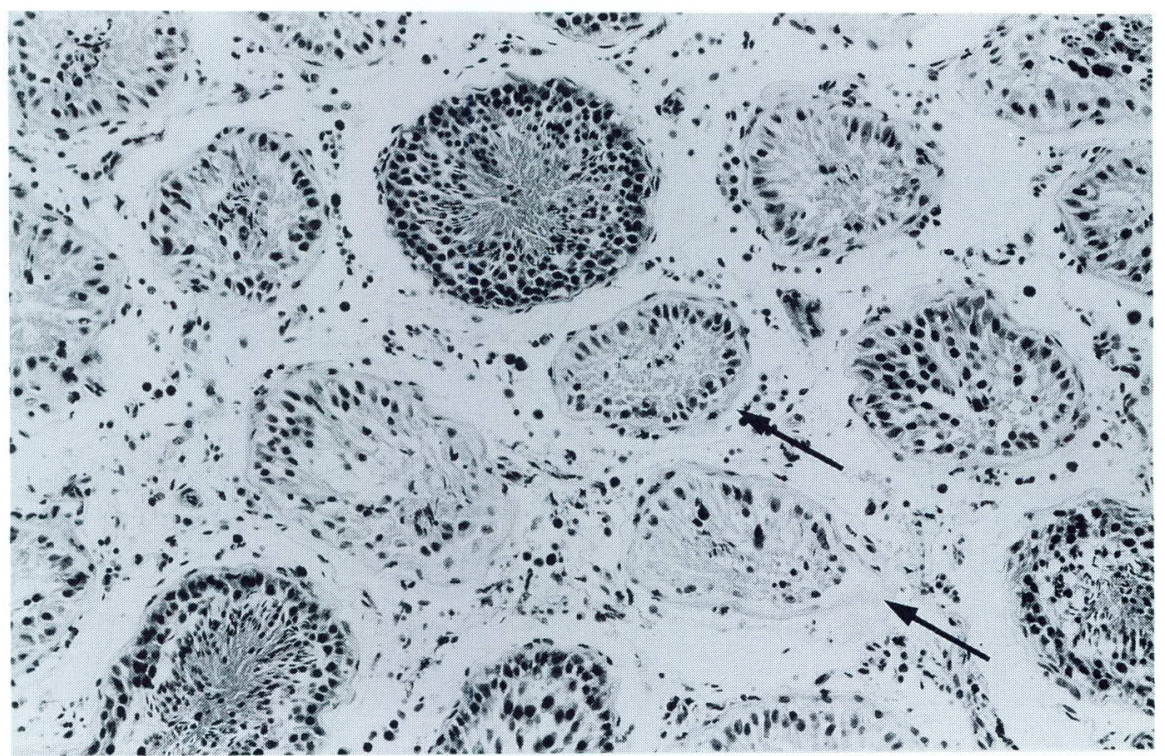

Fig. 5. Seminiferous tubules without spermatogonia in Macaca nemestrina (arrows). Macaca nemestrina (No. 236). 


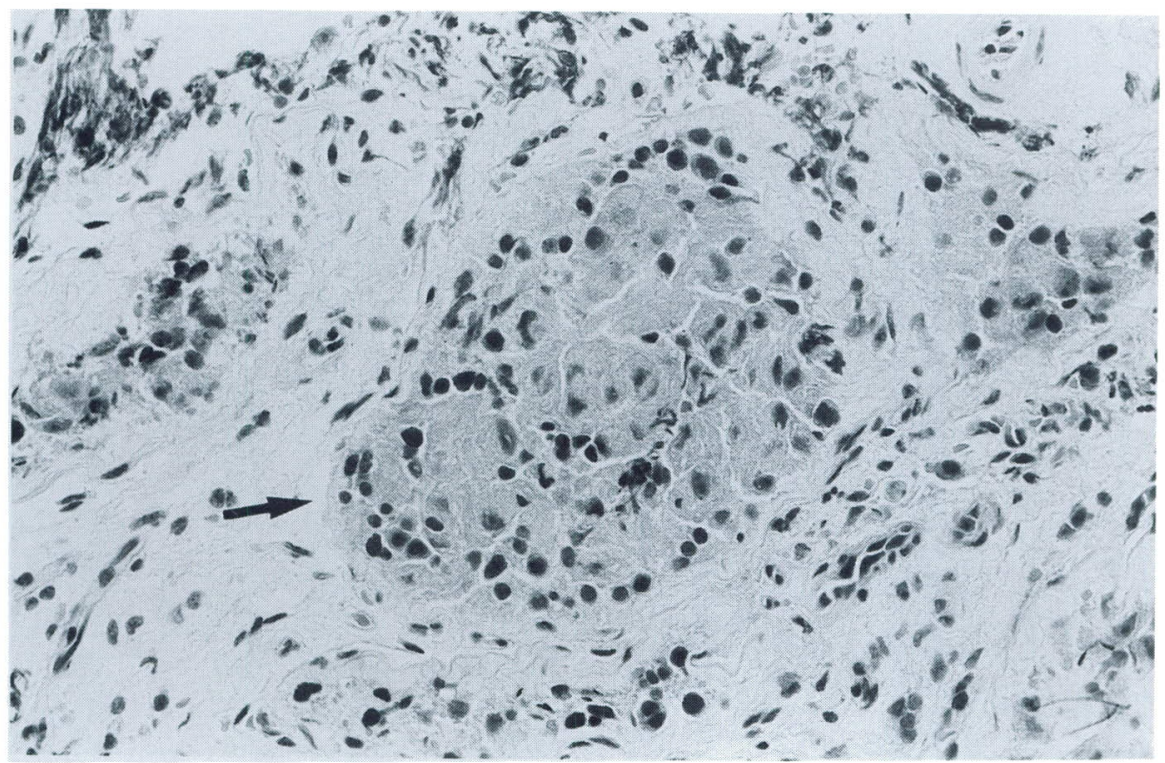

Fig. 6. Seminiferous tubules that showing hyalinization (arrows). Macaca nemestrina (No. 100).

Table 3. Characteristics of testis histology of Macaca nemestrina

\begin{tabular}{cccccc}
\hline Male & $\begin{array}{c}\text { Tubules without } \\
\text { spermatogenesis }\end{array}$ & $\begin{array}{l}\text { Thickness of } \\
\text { basement membrane }\end{array}$ & $\begin{array}{l}\text { Winding of } \\
\text { basement membrane }\end{array}$ & $\begin{array}{l}\text { PAS-stained } \\
\text { spermatogonia }\end{array}$ & $\begin{array}{l}\text { Amount of } \\
\text { ascrosomic system }\end{array}$ \\
\hline 277 & No & thick & winding & Yes & scanty \\
236 & Yes & thick & winding & No & scanty \\
145 & No & thin & little winding & No & plenty \\
100 & Yes & thick & winding & Yes & medium \\
150 & No & thin & little winding & Yes & medium \\
235 & Yes & thick & winding & No & scanty \\
\hline
\end{tabular}

Table 4. Characteristics of testis histology of Macaca fascicularis

\begin{tabular}{lccccc}
\hline Male & $\begin{array}{l}\text { Tubules without } \\
\text { spermatogenesis }\end{array}$ & $\begin{array}{l}\text { Thickness of } \\
\text { basement membrane }\end{array}$ & $\begin{array}{l}\text { Winding of } \\
\text { basement membrane }\end{array}$ & $\begin{array}{l}\text { PAS-stained } \\
\text { spermatogonia }\end{array}$ & $\begin{array}{l}\text { Amount of } \\
\text { ascrosomic system }\end{array}$ \\
\hline 1697 & No & thin & rather winding & No & scanty \\
213 & No & medium & rather winding & No & scanty \\
114 & No & thin & little winding & No & plenty \\
108 & No & thin & little winding & Yes & medium \\
72 & No & thin & little winding & No & medium \\
4998 & No & thin & little winding & No & scanty \\
\hline
\end{tabular}

\section{Characteristics of basement membrane of seminiferous tubules}

Basement membranes, which wrapped up seminiferous tubules, were sometimes thickened with fibrous materials. In the pig-tailed macaque, basement membranes were 
Table 5. Characteristics of testis histology of Macaca fuscata

\begin{tabular}{|c|c|c|c|c|c|}
\hline Male & $\begin{array}{l}\text { Tubules without } \\
\text { spermatogenesis }\end{array}$ & $\begin{array}{l}\text { Thickness of } \\
\text { basement membrane }\end{array}$ & $\begin{array}{l}\text { Winding of } \\
\text { basement membrane }\end{array}$ & $\begin{array}{l}\text { PAS-stained } \\
\text { spermatogonia }\end{array}$ & $\begin{array}{l}\text { Amount of } \\
\text { ascrosomic system }\end{array}$ \\
\hline \multicolumn{6}{|c|}{ April (non-mating season) } \\
\hline Akuta & No & thin & little winding & Yes & scanty \\
\hline Kojiro & No & thin & little winding & Yes & scanty \\
\hline Saki & No & thin & little winding & Yes & scanty \\
\hline Jiro & No & thin & little winding & Yes & scanty \\
\hline Ryota & No & thin & little winding & Yes & scanty \\
\hline \multicolumn{6}{|c|}{ October (mating season) } \\
\hline Akuta & No & thin & little winding & Yes & scanty \\
\hline Kojiro & No & thin & little winding & Yes & scanty \\
\hline Saki & No & thin & little winding & Yes & scanty \\
\hline Jiro & No & thin & little winding & Yes & scanty \\
\hline Ryota & No & thin & little winding & Yes & scanty \\
\hline
\end{tabular}

thickened in four individuals (Table 3), whereas they were rather thin in the crab-eating and Japanese macaques (Tables 4 and 5).

The basement membranes were sometimes observed as being wavy. Basement membranes of four specimens were observed as being a winding type in pig-tailed macaques. Two specimens of crab-eating macaques had rather winding membranes, but the others did not. There was not a testicular specimen with this winding basement membrane in Japanese macaques.

\section{Spermatogonia with PAS-stained granules in their cytoplasm}

Sometimes spermatogonia contained PAS-stained granules in their cytoplasm. In testes of the Japanese macaque, this type of spermatogonia could be easily observed, especially in specimens of the non-mating season (Tables 3 to 5, Fig. 7) as reported by Enomoto et al. (1994). whereas, in specimens of other species, cells of this type were not commonly found.

\section{Amount of acrosomic material}

Spermatids obtain acrosomic materials at their heads in the process of spermiogenesis. The amount of acrosomic materials varied in each individual (Figs. 8 to 10, Tables $3-$ 5). Generally speaking, spermatids with abundant acrosomic materials were most frequently observed in crab-eating macaques, whereas they are comparatively scanty in pig-tailed macaques and especially Japanese macaques.

\section{Spermatocytogenetic activities}

Spermatocytes were found in seminiferous tubules in almost all individuals of the three species except for two pigtailed males, in which the majority of seminiferous 


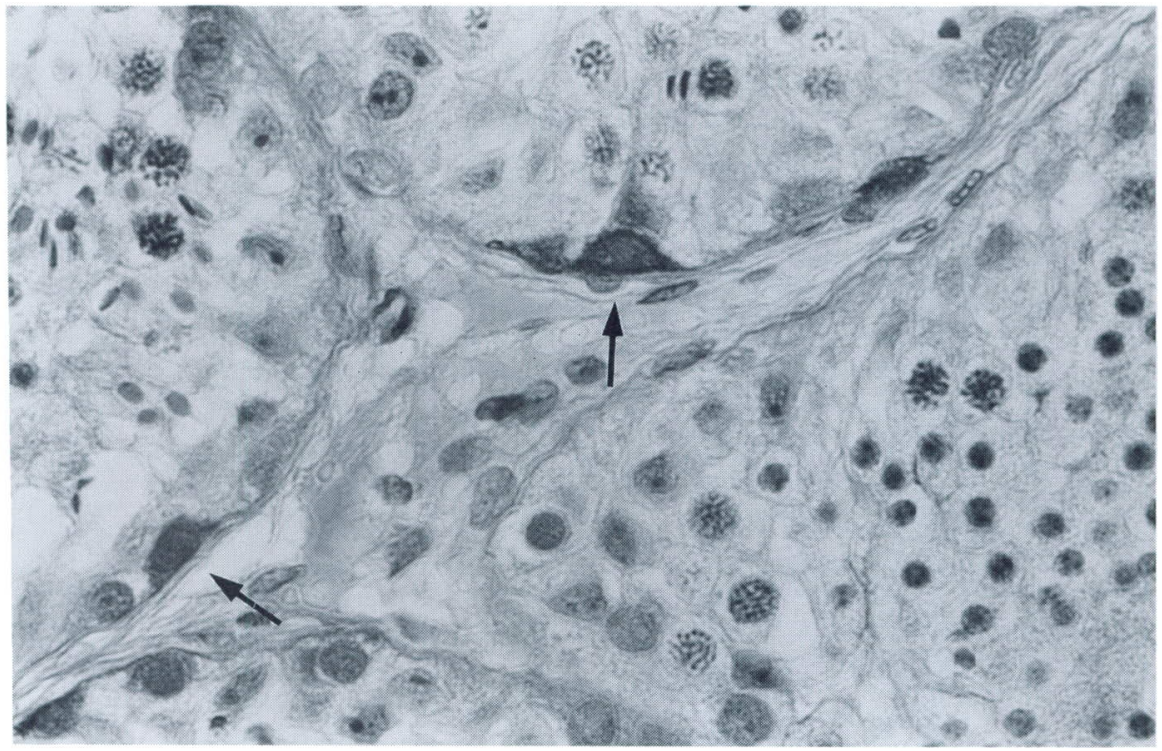

Fig. 7. Spermatogonia with PAS-stained granules in their cytoplasm (arrows). Macaca fuscata (Ryota, April).

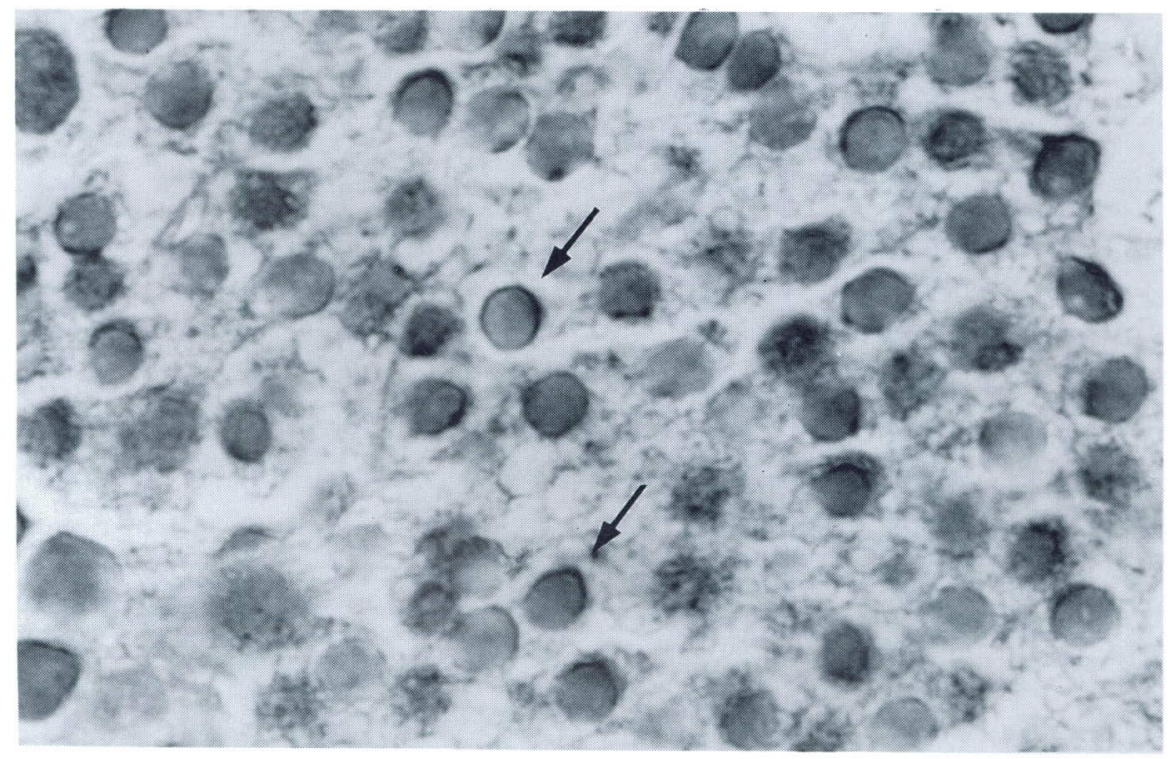

Fig. 8. The acrosomic system of Macaca fascicularis (No. 108) (arrows). Stained with PAS and hematoxylin. 


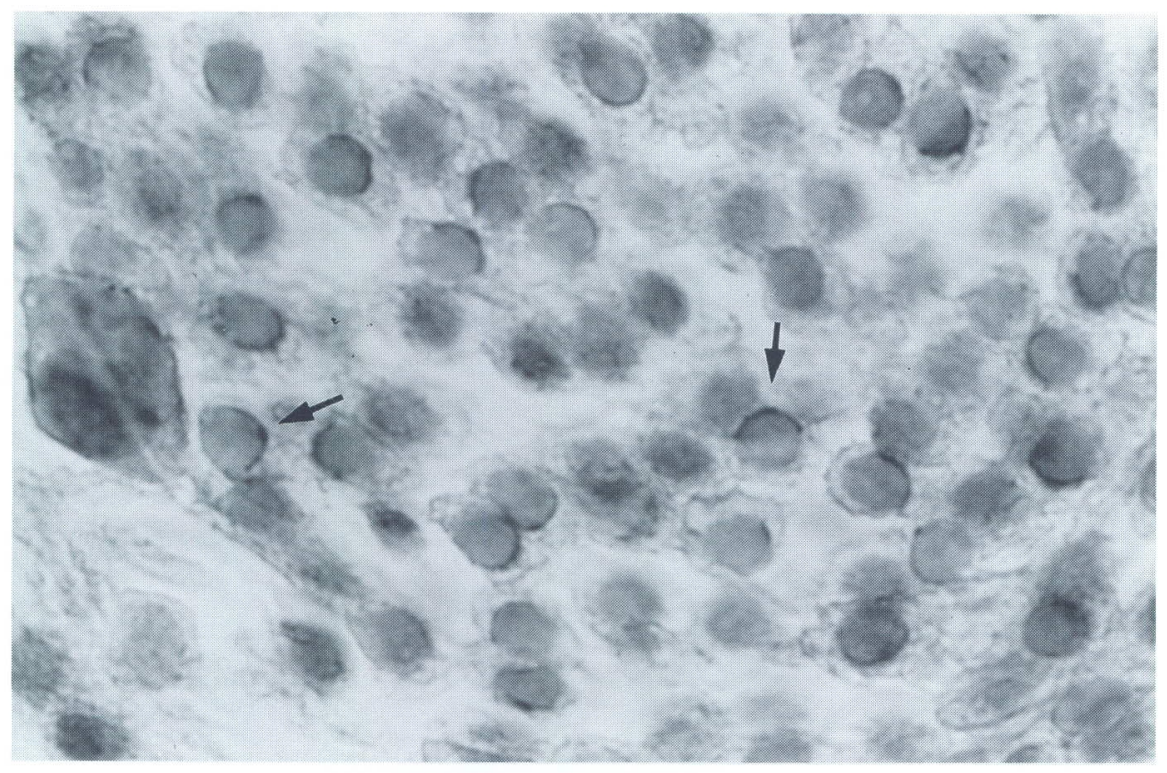

Fig. 9. The acrosomic system of Macaca nemestrina (No. 150) (arrows). Stained with PAS and hematoxylin, $\times 100$.

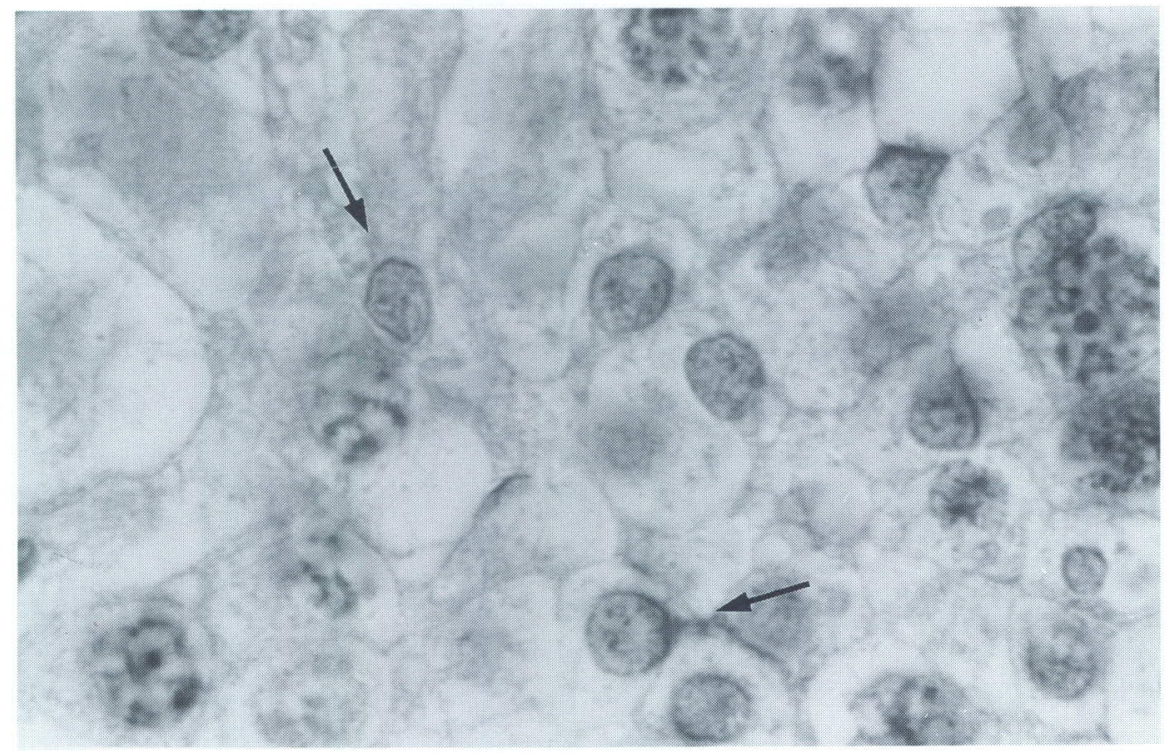

Fig. 10. The acrosomic system of Macaca fuscata (Akuta, April) (arrows). Stained with PAS and hematoxylin, $\times 1000$. 


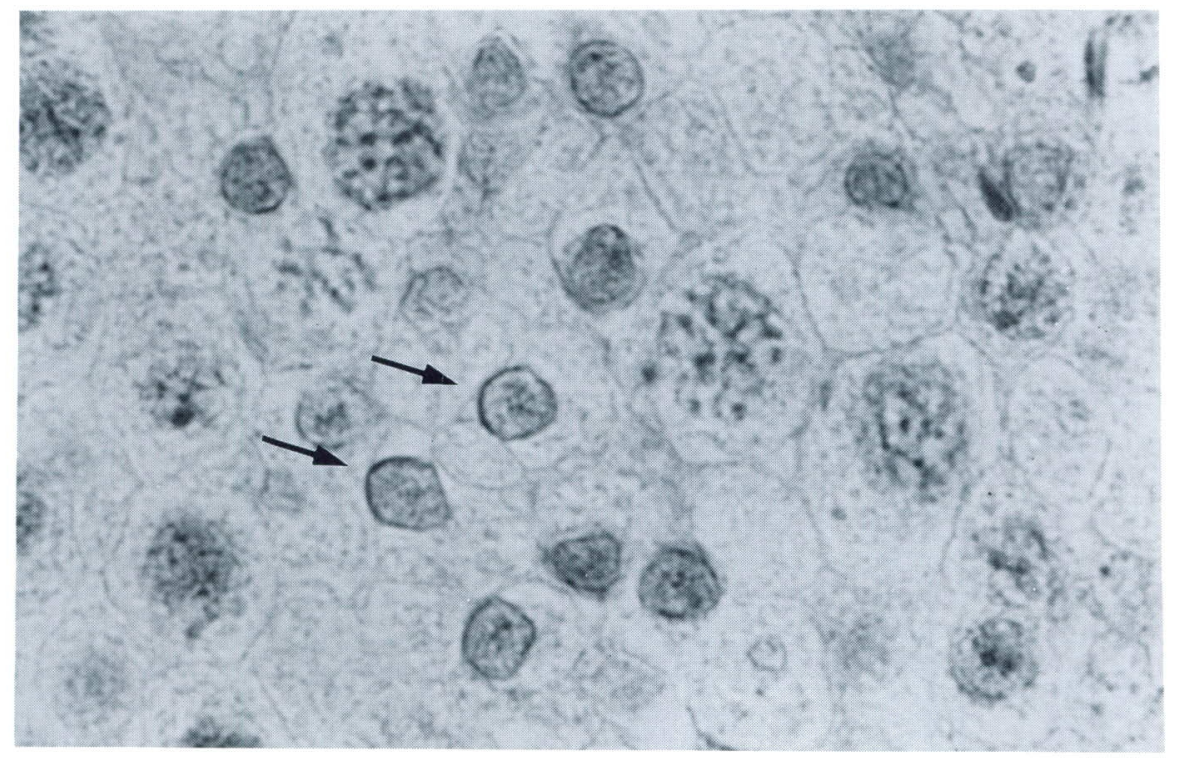

Fig. 11. The acrosomic system of Macaca fuscata (Ryota, October) (arrows). Stained with PAS and hematoxylin, $\times 1000$.

tubules had not spermatocytes (Table 6).

\section{Spermiogenetic activities}

According to spermatogenetic cycles of seminiferous epithelia, stages could be divided into two groups: In a group, two types of spermatids can be observed in the same epithelium, namely spermatids of the maturation phase and immature spermatids. This was equivalent to stages I to $\mathrm{V}$ of the cycle of seminiferous epithelium in the Japanese macaque. In the other group, the seminiferous epithelium contained spermatids of only one type, and this is equivalent to stages VI to X (Nagato et al., 1994).

Tables 7-9 show conditions of seminiferous tubules from each specimen. Analysis of variance (ANOVA) revealed the significant difference of the ratio of tubules in which spermatids of the maturation phase were absent $(\mathrm{F}=3.390 ; \mathrm{df}=3 ; P<0.041)$. Seminiferous tubules of this type were more frequently observed in pig-tailed macaques than in both crab-eating macaques $(t=1.933 ; \mathrm{df}=10 ; P<0.1)$ and Japanese macaques of the mating season $(t=2.195 ; \mathrm{df}=9 ; P<0.1)$. The ratio of the tubules in crab-eating macaques was less than in Japanese macaques in the non-mating season $(t=2.348 ; \mathrm{df}=9 ; P<0.05)$, and also a difference was noticed in Japanese macaques between seasons $(t=3.073$; $\mathrm{df}=8$; $P<0.02)$.

ANOVA showed that the ratio of active seminiferous tubules with many spermatids of the maturation phase was slightly different among species $(\mathrm{F}=2.881 ; \mathrm{df}=3 ; P=0.065)$. This type of tubules was frequently found in pig-tailed macaques and also in crab-eating 
macaques more so than in Japanese macaques of the non-mating season $(t=3.248 ; \mathrm{df}=9$; $P<0.01, t=2.881 ; \mathrm{df}=9 ; P<0.05$, respectively). There were no statistic differences among pig-tailed, crab-eating, and Japanese macaques of the mating season in this ratio.

Table 6. Ratio of tubules with spermatocytes in each macaque species

\begin{tabular}{|c|c|c|c|c|c|c|c|c|c|c|c|}
\hline & \multicolumn{3}{|c|}{ Macaca nemestrina } & \multicolumn{3}{|c|}{ Macaca fascicularis } & \multicolumn{5}{|c|}{$\begin{array}{c}\text { Macaca fuscata } \\
\text { M.s. Nm.s. }\end{array}$} \\
\hline & Male & $\mathrm{Nt}$ & Ratio & Male & $\mathrm{Nt}$ & Ratio & Male & $\mathrm{Nt}$ & Ratio & $\mathrm{Nt}$ & Ratio \\
\hline & 277 & 31 & 0.77 & 1697 & 26 & 0.85 & Kojiro & 25 & 0.96 & 29 & 0.90 \\
\hline & 236 & 50 & 0.46 & 72 & 17 & 0.94 & Ryota & 52 & 0.96 & 38 & 1.00 \\
\hline & 145 & 14 & 0.86 & 4998 & 16 & 0.81 & Akuta & 32 & 1.00 & 36 & 0.97 \\
\hline & 100 & 21 & 0.81 & 108 & 33 & 1.00 & Jiro & 32 & 0.97 & 16 & 0.63 \\
\hline & 150 & 22 & 0.95 & 213 & 22 & 1.00 & Saki & 24 & 0.96 & 55 & 0.78 \\
\hline & 235 & 17 & 0.47 & 114 & 19 & 0.95 & & & & & \\
\hline $\mathrm{N}$ & & & 6 & & & 6 & & & 5 & 5 & \\
\hline mean & & & 0.72 & & & 0.92 & & & 0.97 & & 0.86 \\
\hline s.d. & & & 0.21 & & & 0.08 & & & 0.02 & & 0.15 \\
\hline
\end{tabular}

Nt: Number of tubules observed. M.s.: Mating season; Nm.s.: Non-mating season.

Table 7. Ratio of tubules in grades of spermiogenetic activity in Macaca nemestrina

\begin{tabular}{rrrrrr}
\hline Male & Nt & Active & Medium & Minimum & Absent \\
\hline 277 & 31 & 0.55 & 0.03 & 0.16 & 0.26 \\
236 & 50 & 0.20 & 0.10 & 0.04 & 0.66 \\
145 & 14 & 0.36 & 0.21 & 0.29 & 0.21 \\
100 & 21 & 0.05 & 0.29 & 0.29 & 0.38 \\
150 & 22 & 0.18 & 0.09 & 0.05 & 0.68 \\
235 & 17 & 0.24 & 0.00 & 0.12 & 0.65 \\
\hline & $\mathrm{N}$ & 6 & 6 & 6 & 6 \\
& mean & 0.26 & 0.12 & 0.16 & 0.47 \\
& s.d. & 0.17 & 0.11 & 0.11 & 0.21 \\
\hline
\end{tabular}

Nt: Number of tubules observed. Active, Medium, Minimum: Tubules with many, medium, or poor spermatids of maturation phase, respectively. Absent: tubules without spermatids of maturation phase.

\section{DISCUSSION}

The present study is the first attempt to compare testis histology among closely related primate species. In this study, it is shown that the amount of acrosomic system was plenty, especially in the crab-eating macaques. The content of the acrosomic system, which is stained with PAS because of its rich concentration of glycoproteins (Clermont and Tang, 1985), is composed of various hydrolytic enzymes including acid phosphatases (Thorne-Tjomsland et al., 1988). The acrosomic system has been 
Table 8. Ratio of tubules in grades of spermiogenetic activity in Macaca fascicularis

\begin{tabular}{rrrrrr}
\hline Male & Nt & Active & Medium & Minimum & Absent \\
\hline 1697 & 26 & 0.04 & 0.12 & 0.35 & 0.50 \\
72 & 17 & 0.12 & 0.06 & 0.41 & 0.41 \\
4998 & 16 & 0.75 & 0.13 & 0.00 & 0.13 \\
108 & 33 & 0.55 & 0.12 & 0.09 & 0.24 \\
213 & 22 & 0.82 & 0.00 & 0.05 & 0.14 \\
114 & 19 & 0.32 & 0.37 & 0.16 & 0.16 \\
\hline & $\mathrm{N}$ & 6 & 6 & 6 & 6 \\
& mean & 0.43 & 0.13 & 0.18 & 0.26 \\
& s.d. & 0.33 & 0.13 & 0.17 & 0.16 \\
\hline
\end{tabular}

Nt: Number of tubules observed. Active, Medium, Minimum: Tubules with many, medium, or poor spermatids of the maturation phase, respectively. Absent: tubules without spermatids of the maturation phase.

Table 9a. Ratio of tubules in grades of spermiogenetic activity in Macaca fuscata of the mating season

\begin{tabular}{lrrrrr}
\hline Male & Nt & Active & Medium & Minimum & Absent \\
\hline Kojiro & 25 & 0.00 & 0.08 & 0.64 & 0.28 \\
Ryota & 52 & 0.00 & 0.06 & 0.54 & 0.40 \\
Akuta & 32 & 0.13 & 0.53 & 0.28 & 0.06 \\
Jiro & 32 & 0.28 & 0.31 & 0.16 & 0.25 \\
Saki & 24 & 0.71 & 0.13 & 0.00 & 0.17 \\
\hline & $\mathrm{N}$ & 5 & 5 & 5 & 5 \\
& mean & 0.22 & 0.22 & 0.32 & 0.23 \\
& s.d. & 0.29 & 0.20 & 0.26 & 0.13 \\
\hline
\end{tabular}

Nt: Number of tubules observed. Active, Medium, Minimum: Tubules with many, medium or poor spermatids of maturation phase, respectively. Absent: tubules without spermatids of the maturation phase.

Table 9b. Ratio of tubules in grades of spermiogenetic activity in Macaca fuscata of the non-mating season

\begin{tabular}{lrrrrr}
\hline Male & Nt & Active & Medium & Minimum & Absent \\
\hline Kojiro & 29 & 0.00 & 0.07 & 0.38 & 0.55 \\
Ryota & 38 & 0.00 & 0.13 & 0.47 & 0.39 \\
Akuta & 36 & 0.03 & 0.36 & 0.28 & 0.33 \\
Jiro & 16 & 0.00 & 0.00 & 0.44 & 0.56 \\
Saki & 55 & 0.02 & 0.22 & 0.33 & 0.44 \\
\hline & $\mathrm{N}$ & 5 & 5 & 5 & 5 \\
& mean & 0.01 & 0.16 & 0.38 & 0.46 \\
& s.d. & 0.01 & 0.14 & 0.08 & 0.10 \\
\hline
\end{tabular}

$\mathrm{Nt}$ : Number of tubules observed. Active, Medium, Minimum: Tubules with many, medium, or poor spermatids of maturation phase, respectively. Absent: tubules without spermatids of the maturation phase. 
considered to facilitate so-called acrosome reaction. In Japanese macaques, the acrosomic system is scanty in all individuals in the non-mating season. In the mating season, acrosomic system of some of individuals was enlarged (Enomoto et al., 1994). Among macaque species examined in the present study, the acrosomic system of Japanese macaques was scanty, but still abundant, compared with that of apes and humans (Homo sapiens, Clermont, 1963; Pan troglodytes, Nagato et al., unpublished data; Gorilla gorilla gorilla, Matsubayashi et al., unpublished data). This finding suggests that spermatozoa of genus Macaca, which contain plenty acrosomic system, may be more efficient at the fertilization, compared with those of anthropoids.

The present study also shows that the basement membranes of some specimens of pig-tailed macaques were wound and some were thickened. Because such phenomena were also observed in the testes of aged Japanese macaques (Matsubayashi et al., 1994), such phenomenon was due to the seniority of the males. In human cases of infertility, the basement membrane is often greatly thickened (Fawcett, 1994), and the thickness increases according to age (Yamanaka and Shida, 1984). In extreme cases, seminiferous tubules come to be dysgenesis as shown in individuals of Klinefelter's Syndrome (Grumbach and Conte, 1981). In three specimens out of six of the pig-tailed macaques contained hyalinized tubules resembling this case. Housing conditions of them such as temperature, relative humidity, and lighting were not so different from their native environments. The males were kept in one-male groups in larger cages except for one individual and any pathological signs had not been found in these males. Although the cause of thickness of the basement membranes cannot be resolved in the present study, it might indicate a decline of spermatogenetic activity in these individuals according to their seniority.

Spermatogonia with PAS-positive granules in their cytoplasm were frequently observed in specimens of Japanese macaques. The granules seem to contain glycogen (Clermont and Leblond, 1959), and cells of this type increase in the non-mating season of Japanese macaques (Enomoto et al., 1994). The appearance of this type of cells has been well known in human testes of seminoma (Ashley, 1990). Therefore, appearance of PAS-positive cells seems to indicate an inactive condition of spermatogenesis. That this type of spermatogonia was rarely observed in pig-tailed macaques and crabeating macaques may show the spermatogenesis is active in these species more than Japanese macaques.

Although spermatogenetic activities varied individually, some species-specific features could be noticed. The present study showed that seminiferous tubules without spermatids of the maturation phase were more frequently found in pig-tailed macaques than in crab-eating macaques or Japanese macaques of the mating season. This suggests that these tubules were inactive in spermiogenesis. Moreover, seminiferous tubules with active spermiogenesis were frequently observed in crab-eating macaques and in pigtailed macaques, compared with Japanese macaques of the non-mating season. In 
Japanese macaques, because spermatocytogenesis persists even in the non-mating season (Matsubayashi and Mochizuki, 1982; Nigi et al., 1980; Tiba and Nigi, 1980; Matsubayashi and Enomoto, 1983; Enomoto et al., 1994), many spermatids seem to degenerate in this season (Enomoto et al., 1995). This fact suggests that the architecture of seminiferous epithelium of Japanese macaques has been modulated by environment where they live through their dispersion to a temperature climate.

There are several hypothetical processes can be given that affect testis morphology in primates. The testis may act as a signal for females and act in mate choice. In Japanese macaques, males repeatedly solicit displaying their testes encapsulated in colored scrotum (Enomoto, 1974). The testicular size of Japanese macaques becomes larger in the mating season (Matsubayashi and Enomoto, 1983). Nevertheless, many PASpositive cells were found in seminiferous epithelia and also the acrosomic system of spermatids was scanty, which might indicate that spermatogenesis was inactive. Spermatogenetic activity was not so prominent even then, compared with the crabeating macaque. Therefore, this hypothesis cannot be refuted in this study.

Several researchers (Short, 1979; Harvey and Harcourt, 1984) have proposed the sperm competition hypothesis. The hypothesis predicts that spermatogenesis should be active in species with strict sperm competition. The mean adult sex ratio in the troop of pig-tailed macaques is estimated as 1:6.3 (Oi, 1990), and the most dominant male of the troop frequently mates more than any other troop males (Oi, 1996). But in Japanese macaques, the correlation of rank and frequency of sexual activity is not so clear (Enomoto, 1974, 1978; Takahata, 1982). In crab-eating macaques, a positive correlation between rank and frequency of sexual activity was reported (Shively et al., 1982; van Noordwijk, 1985). However, adult sex ratio is not so large (van Schaik et al., 1983; van Schaik and von Noordwijk, 1988). Therefore, competition among males for courtship may be strict in crab-eating macaques, which should coincide with active spermatogenesis.

However, in the Japanese macaque, findings were rather complicated. As mentioned above, they have large testes, especially in the mating season, but have scanty acrosomic system and many PAS-positive cells. This is partly due to the fact that the species is a seasonal breeder (Matsubayashi and Mochizuki, 1982; Matsubayashi and Enomoto, 1983; Enomoto et al., 1994). Such seasonal fluctuations may affect histological aspects of the testes and also social organization of its species as suggested by Oi (1996).

\section{ACKNOWLEDGEMENTS}

The authors wish to express their thanks to the staff of the Primate Research Center, Bogor Agricultural University, Indonesia and Primate Research Institute, Kyoto University, Japan for their aid during this study. They also wish to thank Dr. Michael Huffman for his language assistance in preparing manuscript. This work was carried out as part of the Co-operation Research Program 1993-1996 of the Primate Research 
Institute, Kyoto University. This study was supported in part by the Grant-in-Aid for Scientific Research (c) from the Ministry of Education, Science, and Culture, Japan (No. 06640924) in 1994-1996.

\section{REFERENCES}

Ashley, D.J.B. (1990) Evans' Histological Appearances of Tumors, Churchill Livingstone, Edinburgh. Cavicchia, J.C., and Dym, A. (1978) Ultrastructural characteristics of monkey spermatogonia and preleptotene spermatocytes. Biol. Reprod. 18, 219-228.

Clermont, Y. (1963) The cycle of the seminiferous epithelium in man. Am. J. Anat. 112, 35-51.

Clermont, Y. (1966) Spermatogenesis in man: A study of the spermatogonial population. Fertil. Steril. 17, 705-721.

Clermont, Y. (1969) Two classes of spermatogonial stem cells in the monkey (Cercopithecus aethiops). Am. J. Anat. 126, 57-72.

Clermont, Y., and Antar, M. (1973) Duration of the cycle of the seminiferous epithelium and the spermatogonial renewal in the monkey Macaca arctoides. Am. J. Anat. 136, 153-166.

Clermont, Y., and Leblond, P. (1955) Spermiogenesis of man, monkey, ram and other mammals as shown by the "periodic acid-Schiff" technique. Am. J. Anat. 96, 229-253.

Clermont, Y., and Leblond, P. (1959) Differentiation and renewal of spermatogonia in the monkey, Macacus rhesus. Am. J. Anat. 104, 237-274.

Clermont, Y., and Tang, X.M. (1985) Glycoprotein synthesis in the Golgi apparatus of spermatids during spermiogenesis of the rat. Anat. Rec. 213, 33-43.

Darwin, C. (1871) The Descent of Man and Selection in Relation to Sex. 2 vols., London, (Translated by Ikeda, J. and Itani, J. into Japanese, Chuokoron, Tokyo (1967)).

Dym, M., and Cavicchia, U.C. (1978) Functional morphology of the testis. Biol. Reprod. 18, 1-15.

Enomoto, T. (1974) The sexual behavior of Japanese monkeys. J. Hum. Evol. 3, 351-372.

Enomoto, T. (1978) On social preference in sexual behavior of Japanese monkeys (Macaca fuscata). J. Hum. Evol. 7, 283-293.

Enomoto, T., Matsubayashi, K., Nagato, Y., and Nakano, M. (1994) Seasonal changes in the spermatogenic epithelium of adult Japanese macaques (Macaca fuscata fuscata). Primates 35, 465-472.

Enomoto, T., Matsubayashi, K., Nagato, Y., and Nakano, M. (1995) Seasonal changes in spermatogenic cell degeneration in the seminiferous epithelium of adult Japanese macaques (Macaca fuscata fuscata). Primates 36, 411-422.

Fawcett, D.W. (1994) A Textbook of Histology, Chapman \& Hall, New York.

Gondos, B., and Zemjanis, A. (1970) Fine structure of spermatogonia and intercellular bridges in Macaca nemestrina. J. Morphol. 131, 431-446.

Grumbach, M.M., and Conte, F.A. (1981) Disorders of sex differentiation. In Textbook of Endocrinology, 6th Ed. (Williams, R.Hl.ed.), W.B. Saunders Co., Philadelphia, pp. 423-514.

Harvey, P.H., and Harcourt, A.H. (1984) Sperm competition, testes size, and breeding system in primates. In Sperm Competition and the Evolution of Animal Mating System (Smith, R.L. ed.), Academic Press, Orlando, pp. 589-600.

Heller, C.G., and Clermont, V. (1963) Spermatogenesis in man, An estimate of its duration. Science 140, 184-186.

Matsubayashi, K., and Mochizuki K. (1982) Growth of male reproductive organs with observation of their seasonal morphologic changes in the Japanese monkey (Macaca fuscata). Jap. J. Vet. Sce. 44, 
891-902.

Matsubayashi, K., and Enomoto T. (1983) Longitudinal studies on annual changes in plasma testosterone, body weight and spermatogenesis in adult Japanese monkeys (Macaca fuscata fuscata) under laboratory conditions. Primates 24, 521-529.

Matsubayashi, K., Enomoto, T., and Nakano, M. (1994) Preliminary report on histological characteristics of male reproductive organs in senile Japanese macaques. Anthropol. Sci. 102 (Suppl.), 199-205.

Nagato, Y., Enomoto, T., and Matsubayashi, K. (1994) Observation on the cycle of the seminiferous epithelium in the Japanese macaque (Macaca fuscata) using semithin sections. Primates 35, 455-464.

Nigi, Y., Tiba, T., and Ohsawa, N. (1980) Sexual maturation and seasonal changes in reproductive phenomena of male Japanese monkeys (Macaca fuscata) at Takasakiyama. Primates 21, 230-240.

Oi, T. (1990) Population organization of wild pig-tailed macaques (Macaca nemestrina nemestrina) in West Sumatra. Primates 31, 15-31.

Oi, T. (1996) Sexual behaviour and mating system of the wild pig-tailed macaque in West Sumatra. In Evolution and Ecology of Macaque Societies (Fa, J.E., and Lindburg, D.G. eds.), Cambrdige Univ. Press, Cambridge, pp. 342-368.

Shiveley, C., Clarke, S., King, N., Schapiro, S., and Mitchell, G. (1982) Patterns of sexual behavior in male macaques. Am. J. Primatol. 2, 373-384.

Short, R.V. (1979) Sexual selection and its component parts, somatic and genital selection, as illustrated by man and the great apes. Adv. Study Behav. 9, 131-158.

Smith, R.L. (1984) Human sperm competition. In Sperm Competition and the Evolution of Animal Mating System (Smith, R.L., ed.), Academic Press, Orlando, pp. 601-659.

Takahata, Y. (1982) The socio-sexual behavior of Japanese monkeys. Zeischrift fur Tierpsychologie 59, 589-108.

Thorne-Tjomsland, G., Clermont, Y., and Hermo, L. (1988) Contribution of the Golgi apparatus components to the formation of the acrosomic system and chromatoid body in rat spermatids. Anat. Rec. 221, 591-598.

Tiba, T., and Nigi, I. (1975) Unregelmaessig aufgebaute Zellgemeinschaften des Samenepithels beim free-ranging japanischen Makak (Macaca fuscata) in der Paarungszeit. Primates 16, 379-398.

Tiba, T., and Nigi, I. (1980) Jahreszeitliche Schwankung in der Spermatogenese beim "free-ranging" Japanischen Makak (Macaca fuscata). Zool. Anz. 204, 371-387.

van Noordwijk, M.A. (1985) Sexual behaviour of Sumatran long-tailed macaques (Macaca fascicularis). Zeitschrift für Tierpsychologie 70, 277-296.

van Schaik, C.P., and van Noordwijk, M.A. (1988) Scramble and contest in feeding competition among female long-tailed macaques (Macaca fascicularis). Behaviour 105, 77-98.

van Schaik, C.P., van Noordwijk, M.A., de Boer, R.J., and den Tonkelaar, I. (1983) The effect of group size on time budgets and social behaviour in wild long-tailed macaques (Macaca fascicularis). Behav. Ecol. Scoiobiol. 13, 173-181.

Yamanaka, H., and Shida, K. (1984) Function of the testis and its again. In Shin Rinsho Hinyoukika Zensho Vol. 8A, Function and Dysfunction of the Testis (Tsuji, I. et al. eds.), Kanahara, Tokyo, pp. 79-91. (In Japanese) 